\title{
Successful Fontan procedure for asplenia with pulmonary atresia and major aortopulmonary collateral arteries
}

\author{
Kagami Miyaji, MD, ${ }^{\text {a }}$ Nobuhiro Nagata, MD, ${ }^{\text {a }}$ Hikoro Matsui, MD, ${ }^{\mathrm{b}}$ Takashi Miyamoto, \\ $\mathrm{MD}^{\mathrm{a}}$ and Kazuo Kitahori, MD, ${ }^{a}$ Yokohama, Japan
}

A splenia with a single ventricle and major aortopulmonary collateral arteries (MAPCAs) is a rare congenital cardiac anomaly. In this patient group achievement of the Fontan procedure depends on ample rehabilitation of the pulmonary arteries to secure sufficient pulmonary vascular beds and the prevention of progressive pulmonary vascular obstructive disease. Here we report a successful 1-stage bilateral unifocalization of the pulmonary blood supply followed by a staged Fontan procedure in a patient with a univentricular heart and MAPCAs.

\section{Clinical Summary}

The patient was given a diagnosis of asplenia, univentricular heart (right ventricular type), common atrioventricular orifice, pulmonary atresia, bilateral superior vena cavas, total anomalous pulmonary venous connection (intracardiac type), and MAPCAs on the basis of echocardiography and cardiac catheterization. His neonatal aortography showed a small central pulmonary artery $(3 \mathrm{~mm}$ in diameter) and bilateral multiple MAPCAs (Figure 1, A). The patient's arterial oxygen saturation $\left(\mathrm{SaO}_{2}\right)$ was around $80 \%$, and his pulmonary/systemic blood flow ratio (Qp/Qs) was 1.6 with stable hemodynamics. Subsequent cardiac catheterization at 6 month of age revealed a good-sized central pulmonary artery (Figure $1, B$ ) and 5 large MAPCAs. $\mathrm{His}^{\mathrm{SaO}_{2}}$ was approximately $87 \%$, and his Qp/Qs had increased to 3.7. At 1 year of age, he underwent a primary complete unifocalization of his bilateral pulmonary arteries, total anomalous pulmonary venous connection repair for progressive pulmonary venous obstruction (Figure 2), and a left modified Blalock-Taussig shunt (polytetrafluoroethylene [PTFE], * $5 \mathrm{~mm}$ ). The postoperative course was uneventful except for transient bilateral phrenic nerve palsy. He subsequently did well, while becoming increasingly cyanotic. A catheterization at 2

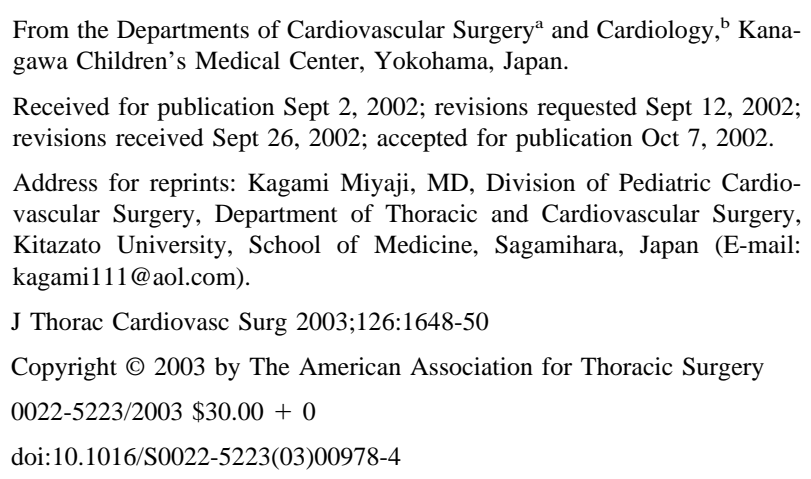

*Gore-Tex shunt, registered trademark of W. L. Gore \& Associates, Inc, Newark, Del. years of age revealed peripheral pulmonary stenosis, low pulmonary vascular resis-

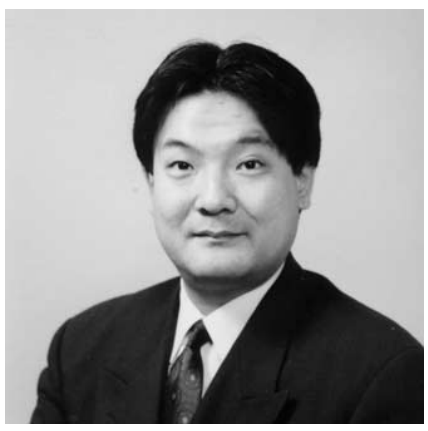

Dr Miyaji tance (1.2 Wood units), and normal pulmonary blood flow $(\mathrm{Qp} / \mathrm{Qs}=1.0)$. The patient then underwent a bilateral bidirectional cavopulmonary shunt and take down of his left modified Blalock-Taussig shunt without cardiopulmonary bypass. This postoperative course was also uneventful, with an $\mathrm{SaO}_{2}$ of $85 \%$ and superior vena caval pressure of $10 \mathrm{~mm}$ $\mathrm{Hg}$. Eight months after the bilateral bidirectional cavopulmonary shunt, a cardiac catheterization was performed, demonstrating good-shaped pulmonary arteries (Figure 3), low pulmonary vascular resistance $\left(1.4 \mathrm{R}^{*} \mathrm{U}\right)$, low pulmonary artery pressure (mean, $10 \mathrm{~mm} \mathrm{Hg}$ ), and low pulmonary blood flow (Qp/Qs $=0.8$ ). Two weeks before definitive surgical intervention, he underwent balloon angioplasty for peripheral pulmonary stenoses and coil embolization of aortopulmonary collateral arteries. At 3 years of age, a fenestrated modified Fontan procedure was performed. An 18-mm PTFE tube graft with a 4-mm PTFE tube graft anastomosed in end-to-side fashion was used for the extracardiac total cavopulmonary connection. The 4-mm PTFE tube graft was anastomosed to the common atrium as a fenestration. The patient was hemodynamically stable intraoperatively, with superior vena caval and inferior vena caval pressures of $11 \mathrm{~mm} \mathrm{Hg}$, a common atrial pressure of $4 \mathrm{~mm} \mathrm{Hg}$, and an $\mathrm{SaO}_{2}$ of $94 \%$. The patient returned to the cardiovascular intensive care unit in stable condition and was extubated 3 hours after the operation. His postoperative course was uneventful. He was transferred to the general ward on the first postoperative day and discharged home 13 days later without any complications.

Three months after the Fontan procedure, another cardiac catheterization was performed, demonstrating a spontaneously occluded tube graft fenestration, an $\mathrm{SaO}_{2}$ of $96 \%$, low pulmonary artery pressure (mean, $12 \mathrm{~mm} \mathrm{Hg}$ ), and excellent Fontan circulation.

\section{Discussion}

A morphologic study showed that abnormal arborization of the pulmonary artery was present in 4 of 125 autopsied specimens with right isomerism (3\%). ${ }^{1}$ Uemura and colleagues ${ }^{2}$ also reported that among 134 patients with right isomerism who underwent surgical interventions, only $3(2 \%)$ patients had MAPCAs. In pulmonary atresia and ventricular septal defect with MAPCAs, initial unifocalization of MAPCAs has been reported to recruit maximum bronchopulmonary segments. ${ }^{3}$ The natural course of these MAPCAs often follows progressive stenosis and occlusion, resulting in loss of some lung segments. As a result, unobstructed 


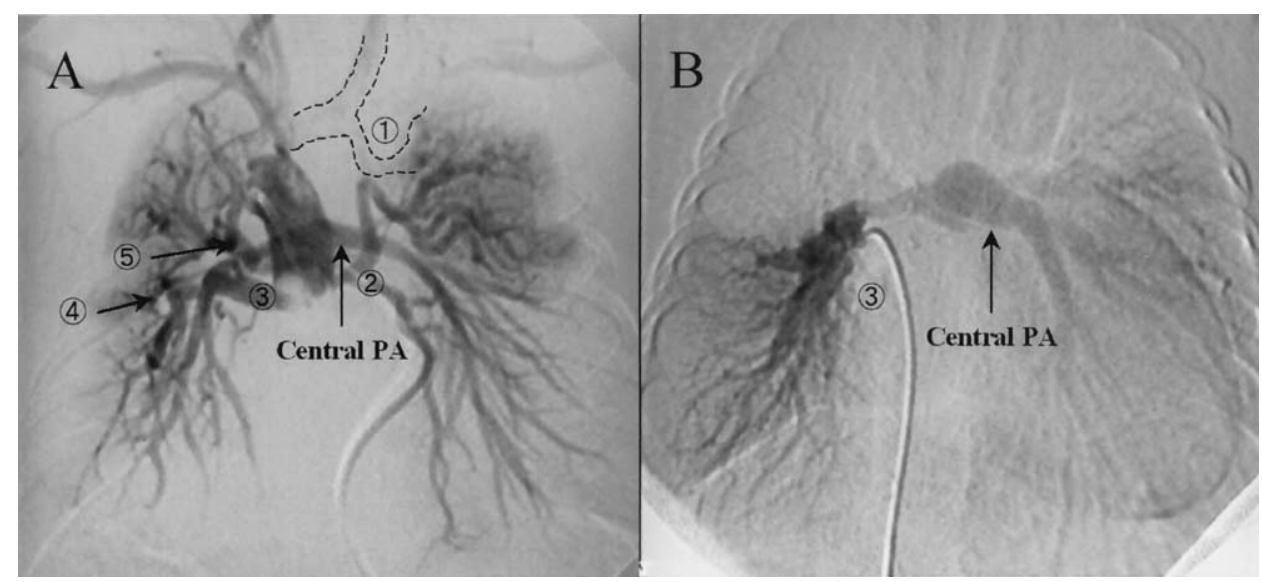

Figure 1. A, Aortography of the neonate showed a small central pulmonary artery ( $<3 \mathrm{~mm}$ in diameter) and 5 MAPCAs. B, Cardiac catheterization at 6 months of age revealed a good-sized central pulmonary artery. The number 3 MAPCA connected to the central pulmonary artery. Then this MAPCA was ligated at the proximal side, and the other 4 MAPCAs were unifocalized to the central pulmonary artery. PA, Pulmonary artery.

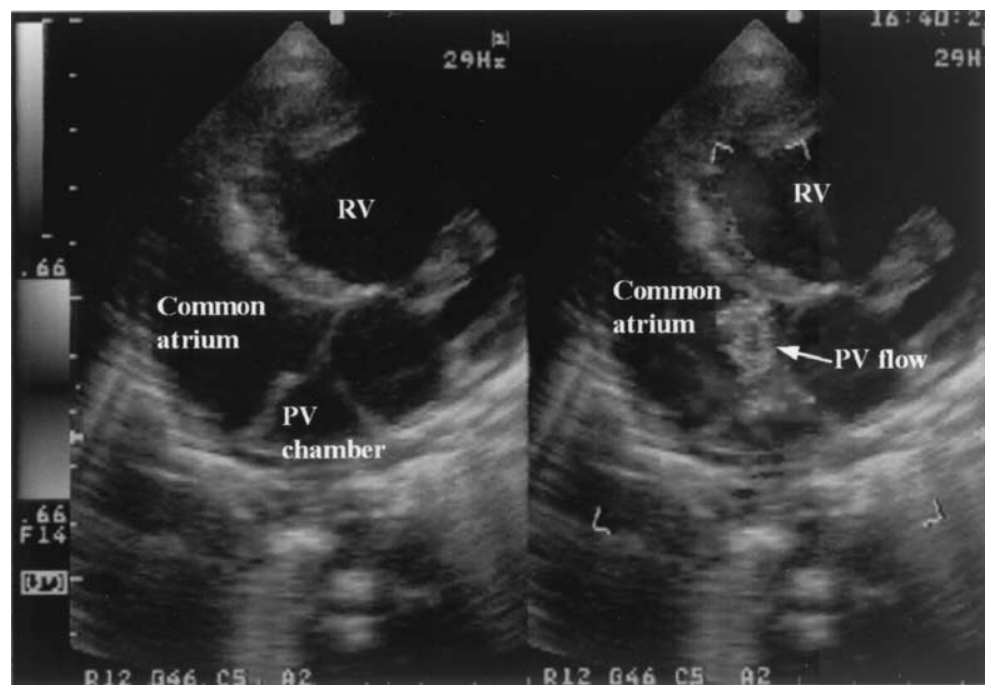

Figure 2. Echocardiography demonstrated total anomalous pulmonary venous connection (intracardiac type) with pulmonary venous obstruction. $R V$, Right ventricle; $P V$, pulmonary venous flow.

MAPCAs can ultimately and rapidly lead to pulmonary vascular obstructive disease in their supplied segment. When 15 or more bronchopulmonary segments are connected to the central pulmonary arteries, unifocalization to incorporate additional segments is not necessary to reduce the pulmonary artery resistance in biventricular physiology. ${ }^{4}$ However, in single-ventricle physiology, there have been no reports on how many bronchopulmonary segments should be connected to the central pulmonary artery to achieve the low pulmonary vascular resistance essential to Fontan circulation. Therefore surgeons have to connect as many MAPCAs as possible to the central pulmonary artery.

Midline 1-staged unifocalization and complete repair for pulmonary atresia and ventricular septal defect with MAPCAs have been reported with excellent results. ${ }^{5}$ Although technical difficul- ties, prolonged operative time, need to implant a prosthetic graft, and stenoses or growth limitation of anastomotic sites serve to limit the potential usefulness of unifocalization procedures in early infants, staged unifocalization with a systemic-pulmonary shunt might result in pulmonary vascular obstructive disease. In our case the size of the central pulmonary artery and MAPCAs in the neonate was diminutive $(<3.0 \mathrm{~mm})$, and catheterization at 6 months of age showed a good-sized central pulmonary artery ( $>6.0 \mathrm{~mm}$ in diameter) and MAPCAs $(>4.0 \mathrm{~mm}$ in diameter). Then at 1 year of age, a 1-stage complete unifocalization was successfully carried out. Subsequent catheter intervention for progressive peripheral pulmonary stenoses and minor aortopulmonary collateral arteries was practical in rehabilitation of the pulmonary arteries to secure sufficient pulmonary vascular beds. 


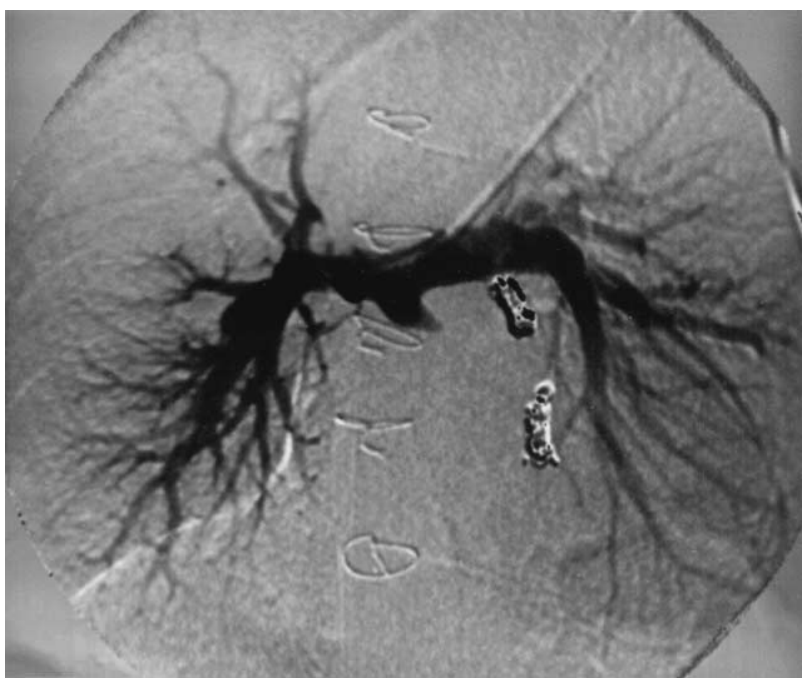

Figure 3. Angiography of the pulmonary artery after a bilateral bidirectional cavopulmonary shunt revealed almost complete unifocalization of the pulmonary artery.
In conclusion, the midline 1-staged unifocalization followed by a staged Fontan procedure is an effective strategy for patients having a univentricular heart and pulmonary atresia with MAPCAs.

\section{References}

1. Uemura H, Ho SY, Anderson RH, Yagihara T. Ventricular morphology and coronary arterial anatomy in hearts with isomeric atrial appendages. Ann Thorac Surg. 1999;67:1403-11.

2. Uemura H, Yagihara T, Kawahira Y, Yoshikawa Y. Staged Unifocalization and anatomic repair in a patient with right isomerism. Ann Thorac Surg. 2001;71:2039-41.

3. Reddy VM, Liddicoat JR, Hanley FL. Midline one-stage complete unifocalization and repair of pulmonary atresia with ventricular septal defect and major aortopulmonary collaterals. $J$ Thorac Cardiovasc Surg. 1995;109:832-45.

4. Shimazaki Y, Tokuan Y, Lio M, Nakano S, Matsuda H, Blackstone EH, et al. Pulmonary artery pressure and resistance late after repair of tetralogy of Fallot with pulmonary atresia. J Thorac Cardiovasc Surg. 1990;100:425-40.

5. Tchervenkov CI, Salasidis G, Cecere R, Beland MJ, Jutras L, Paquet M, et al. One-stage midline unifocalization and complete repair in infancy versus multiple-stage unifocalization followed by repair for complex heart disease with major aortopulmonary collaterals. J Thorac Cardiovasc Surg. 1997;114:727-37.

\title{
Closed correction of systemic semilunar valve insufficiency in the neonate
}

\author{
Frank A. Pigula, MD, ${ }^{\text {a }}$ C. Becket Mahnke, MD, ${ }^{\text {b }}$ Petros Agnastopolous, MD, ${ }^{\text {a }}$ Alfonso Casta, MD, ${ }^{\text {a }}$ Ricardo Munoz, MD, \\ and Sanjiv K. Gandhi, MD, ${ }^{\text {a }}$ Pittsburgh, $\mathrm{Pa}$
}

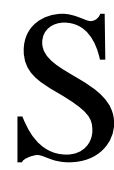

ystemic semilunar valve regurgitation can be a lifethreatening hemodynamic lesion in the neonate with congenital heart disease. Although congenital aortic stenosis remains a vexing problem, a number of interventions have been designed to provide relief. Unfortunately, procedures designed to provide a more competent systemic semilunar valve in the neonate are limited. The reproducibility of reparative techniques might be unpredictable, and prosthetics are limited to small-caliber homografts; both approaches require cardiopulmo-

\footnotetext{
From the Divisions of Pediatric Cardiothoracic Surgery ${ }^{\mathrm{a}}$ and Pediatric Cardiology, ${ }^{\mathrm{b}}$ Children's Hospital of Pittsburgh, Pittsburgh, Pa.

Received for publication April 15, 2003; accepted for publication April 29, 2003.

Address for reprints: Frank A. Pigula, MD, Pediatric Cardiothoracic Surgery, Room 2820, 2 Main, Children's Hospital of Pittsburgh, Pittsburgh, PA 15213 (E-mail: frank.pigula@chp.edu).

J Thorac Cardiovasc Surg 2003;126:1650-2

Copyright $\odot 2003$ by The American Association for Thoracic Surgery $0022-5223 / 2003 \$ 30.00+0$

doi:10.1016/S0022-5223(03)01016-X
}

nary bypass. We describe our experience with a surgical technique that treats systemic semilunar valve regurgitation in the neonate without the need for cardiopulmonary bypass.

\section{Clinical Summary}

Patient 1 was 5-day-old boy given a diagnosis of truncus arteriosus (type IA) with interrupted aortic arch type A. The truncal valve was moderately stenotic (predicted gradient, $40 \mathrm{~mm} \mathrm{Hg}$ ) with moderate-to-severe insufficiency. At the time of the operation, a nodular, 4-leaflet truncal valve was found that was composed of 3 major and 1 minor leaflets. The minor leaflet was sutured to the adjacent leaflets in an attempt reduce the regurgitation.

Attempts at weaning from cardiopulmonary bypass met with low systemic blood pressures and increased left atrial pressures. Transesophageal echocardiography (TEE) showed moderate-tosevere truncal valve regurgitation. With the heart beating and off bypass, pledgeted 4-0 Prolene sutures were passed along the ventriculoarterial junction at the predicted level of the leaflet insertion into the truncal valve annulus. With continuous TEE imaging, the annuloplasty stitch was tightened until regurgitation was reduced from moderate-severe to trivial-mild, without stenosis (Figure 1, $A$ and $B$, and Figure 2). Hemodynamics responded appropriately, and the patient was weaned from bypass without incident. At 6 